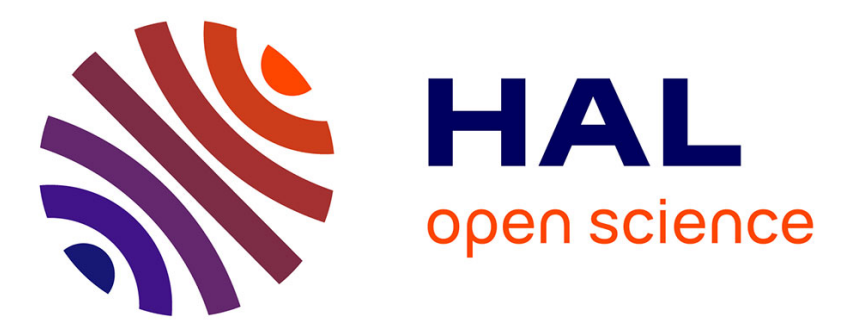

\title{
Conjugate observations on board a satellite and on the ground of a remarkable MLR-like event
}

F. Němec, T. Raita, Michel Parrot, O. Santolik, T. Turunen

\section{To cite this version:}

F. Němec, T. Raita, Michel Parrot, O. Santolik, T. Turunen. Conjugate observations on board a satellite and on the ground of a remarkable MLR-like event. Geophysical Research Letters, 2009, 36, 10.1029/2009gl040974 . insu-03036134

\section{HAL Id: insu-03036134 https://hal-insu.archives-ouvertes.fr/insu-03036134}

Submitted on 2 Dec 2020

HAL is a multi-disciplinary open access archive for the deposit and dissemination of scientific research documents, whether they are published or not. The documents may come from teaching and research institutions in France or abroad, or from public or private research centers.
L'archive ouverte pluridisciplinaire HAL, est destinée au dépôt et à la diffusion de documents scientifiques de niveau recherche, publiés ou non, émanant des établissements d'enseignement et de recherche français ou étrangers, des laboratoires publics ou privés. 


\title{
Conjugate observations on board a satellite and on the ground of a remarkable MLR-like event
}

\author{
F. Němec, ${ }^{1,2,3}$ T. Raita, ${ }^{4}$ M. Parrot, ${ }^{1}$ O. Santolík, ${ }^{2,3}$ and T. Turunen ${ }^{4}$ \\ Received 13 September 2009; revised 20 October 2009; accepted 22 October 2009; published 20 November 2009.
}

[1] Electromagnetic waves observed by low-altitude satellites and on the ground have sometimes - when represented as a frequency-time spectrogram - a form of several nearly parallel and almost equidistant clearly defined lines at frequencies between 1 and $8 \mathrm{kHz}$. These may drift in frequency and they are usually called Magnetospheric Line Radiation (MLR). Although they have been known for a long time, their origin is still unclear. We present an experimental study using both ground-based and satellite data, showing for the first time a detailed analysis of the simultaneous observations of an MLR-like event on the ground and in the conjugate region. We demonstrate that the individual lines forming the event result (at least in this particular case) from elements reflected between the northern and southern hemispheres. Citation: Němec, F., T. Raita, M. Parrot, O. Santolík, and T. Turunen (2009), Conjugate observations on board a satellite and on the ground of a remarkable MLR-like event, Geophys. Res. Lett., 36, L22103, doi:10.1029/2009GL040974.

\section{Introduction}

[2] Electromagnetic waves in the magnetosphere - when represented as a frequency-time spectrogram - sometimes take a form of several nearly parallel and almost equidistant clearly defined lines. These may drift in frequency and they are usually called Magnetospheric Line Radiation (MLR). Such Very Low Frequency (VLF) radio emissions have been observed both by ground-based instruments [e.g., Rodger et al., 1999, 2000a, 2000b; Manninen, 2005] and low-altitude satellites [e.g., Rodger et al., 1995; Parrot et al., 2005, 2006a, 2007; Nëmec et al., 2007, 2009]. However, their origin is still not certain. A detailed analysis of some MLR-like events observed by the low-altitude spacecraft has enabled us to demonstrate that one can distinguish a class of events called Power Line Harmonic Radiation (PLHR), whose frequency spacing is $50 / 100 \mathrm{~Hz}$ or $60 / 120 \mathrm{~Hz}$ [Nëmec et al., 2007]. These are generated by electromagnetic radiation from electric power systems on the ground and should not be confused with MLR [Němec et al., 2008].

[3] Parrot et al. [2007] used simultaneous measurements on the ground and on board the DEMETER satellite to perform a case study of a large-scale MLR event. They reported the enormous size (area of about 7,400,000 $\mathrm{km}^{2}$ ) and time duration ( 2 hours) of the event and demonstrated the

\footnotetext{
${ }^{1}$ Laboratoire de Physique et Chimie de l'Environnement et de l'Espace, CNRS, Orléans, France.

${ }^{2}$ Institute of Atmospheric Physics, ASCR, Prague, Czech Republic.

${ }^{3}$ Faculty of Mathematics and Physics, Charles University, Prague, Czech Republic.

${ }^{4}$ Sodankylä Geophysical Observatory, Sodankylä, Finland.
}

Copyright 2009 by the American Geophysical Union. 0094-8276/09/2009GL040974 power of conjugate observations on the ground and on board satellites. Bullough [1995] suggested the possibility that MLR could originate from PLHR by nonlinear wave-particle interactions taking place in the equatorial region. This idea was further studied by Nunn et al. [1999] using numerical simulations and also adopted by Parrot et al. [2007]. Finally, Němec et al. [2009] reported an event consisting of both PLHR and MLR that occurred during the same satellite orbit and which were located in conjugate regions.

[4] In this paper we report a case study of an MLR-like event with a large frequency drift composed of two different frequency bands observed both by ground-based instruments and by the low-altitude DEMETER satellite, showing that the observations can be explained by VLF elements which are reflected back and forth between the hemispheres along the magnetic field line. Section 2 describes the DEMETER satellite and the wave experiment on board as well as the ground-based experiments. The detailed observations of a most unusual MLR-like event are reported in Section 3. Finally, they are discussed and summarized in Section 4.

\section{DEMETER Satellite and Ground-Based Experiments}

[5] DEMETER is a low-altitude satellite (the original altitude of $710 \mathrm{~km}$ was decreased to $660 \mathrm{~km}$ in December, 2005) launched in June, 2004 into a nearly Sun-synchronous (10:30 LT and 22:30 LT) polar orbit. It measures electromagnetic waves and plasma parameters all around the Earth except at geomagnetic latitudes larger than 65 degrees. There are two different modes of the satellite, called "Burst" and "Survey". In the VLF range (up to $20 \mathrm{kHz}$ ) in which we are interested, power spectra of one electric and one magnetic field component are calculated on board every $2 \mathrm{~s}$ (frequency resolution $19.53 \mathrm{~Hz}$ ) during the Survey mode. During the Burst mode, the waveform of one electric and one magnetic field component is available (sampling frequency $40 \mathrm{kHz}$ ). The Burst mode is active only above some specific geographic areas, typically lasting a few minutes. A more detailed description of the satellite and the wave experiments on board was given by Berthelier et al. [2006] and Parrot et al. [2006b].

[6] The ground-based experiment was located at Kannuslehto, Finland $\left(67.74^{\circ} \mathrm{N}, 26.27^{\circ} \mathrm{E}, L=5.34\right)$ and consisted of two orthogonal coaxial cable aerials with the effective area of $1000 \mathrm{~m}^{2}$ each [Manninen, 2005, p. 33]. The signal was sampled at $78.125 \mathrm{kHz}$ and digitized with 24-bit precision. Timing for the sampling was made with a $10 \mathrm{MHz}$ GPS reference clock.

\section{Conjugate Observations of an MLR-Like Event}

[7] Figure 1 represents a map of the area close to the studied event. The position of Kannuslehto is marked by the 


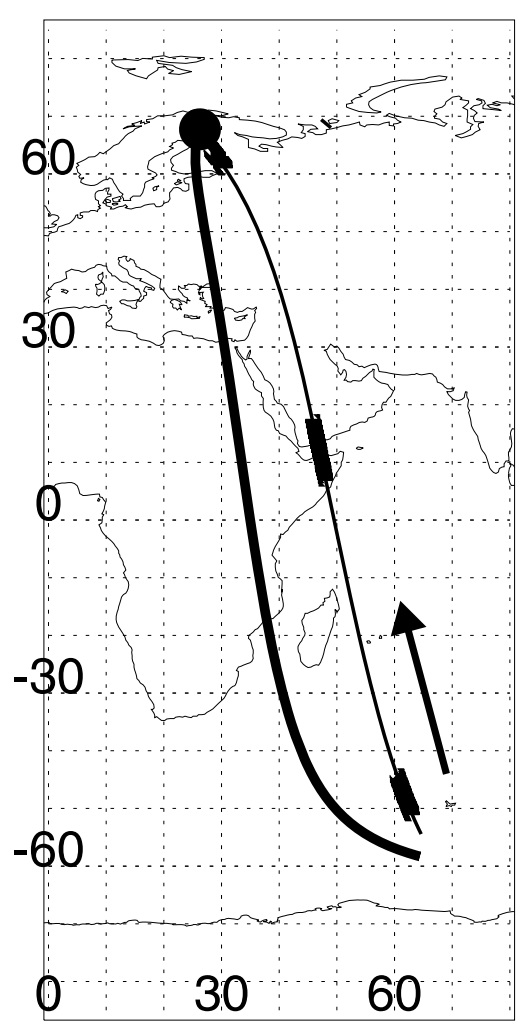

Figure 1. Map showing the areas close to the MLR-like events studied. The position of Kannuslehto station is marked by the solid circle. The thick black line shows the projection of the magnetic field line starting at Kannuslehto station. The projection of the orbit of the DEMETER satellite is plotted by the thinner line. The areas where the line gets thicker mark the locations where the Burst mode was active.

solid circle. The thick black line shows the projection of the magnetic field line starting at the Kannuslehto station. At this station, an MLR-like event was observed on March 1, 2008. It started at about 17:30 UT and lasted up to nearly 20:00 UT. The frequency range of the event was between 2 and $4 \mathrm{kHz}$. It occurred almost continuously for all the 2.5 hours and it consisted of two distinct frequency bands. For most of the time these were observed simultaneously, but sometimes only one of them was present. They were composed of series of individual elements. These series typically lasted a few minutes (a few tens of elements) and had gradual beginning and end. We were lucky enough that DEMETER passed above Kannuslehto at the same time when the event was observed by the ground-based instruments. Moreover, the Burst mode was active during that time and it was also active during the time when DEMETER passed very close to the magnetically conjugate region. The projection of the appropriate orbit of the DEMETER spacecraft is plotted by the thinner line. The areas where the line gets thicker mark the locations where DEMETER was in the Burst mode.

[8] Figure 2 represents the data recorded during the time when DEMETER was in the Burst mode and passing nearby Kannuslehto after 19:06:03 UT. Figure 2 (top) shows a frequency-time spectrogram of the power spectral density of the signal recorded on the ground, while Figure 2 (middle) shows the corresponding frequency-time spectrogram recorded on board DEMETER. It can be seen that basically the same phenomenon is observed, although the satellite data additionally contain intense discrete emissions that come probably from the magnetosphere and do not have the proper orientation of the wave vector to reach the ground. There are two sets of nearly parallel lines. The first of them consists of falling tones and is located at frequencies between about $2400 \mathrm{~Hz}$ and $2800 \mathrm{~Hz}$. The second set of lines consists of rising tones occurring at frequencies between about $3100 \mathrm{~Hz}$ and $3600 \mathrm{~Hz}$. Between these two sets of lines there is a gap of about $300 \mathrm{~Hz}$ where no particular emissions are observed. The situation is schematically represented Figure 2 (bottom). The plotted lines represent a simple approximation of the individual elements observed in Figures 2 (top) and 2 (middle) (determined manually by fitting a single line to each of them). The blue lines correspond to the ground-based data from Figure 2 (top) and the red lines correspond to the satellite data from Figure 2 (middle). The accuracy of timing is approximately $0.25 \mathrm{~s}$. Within this accuracy there is an
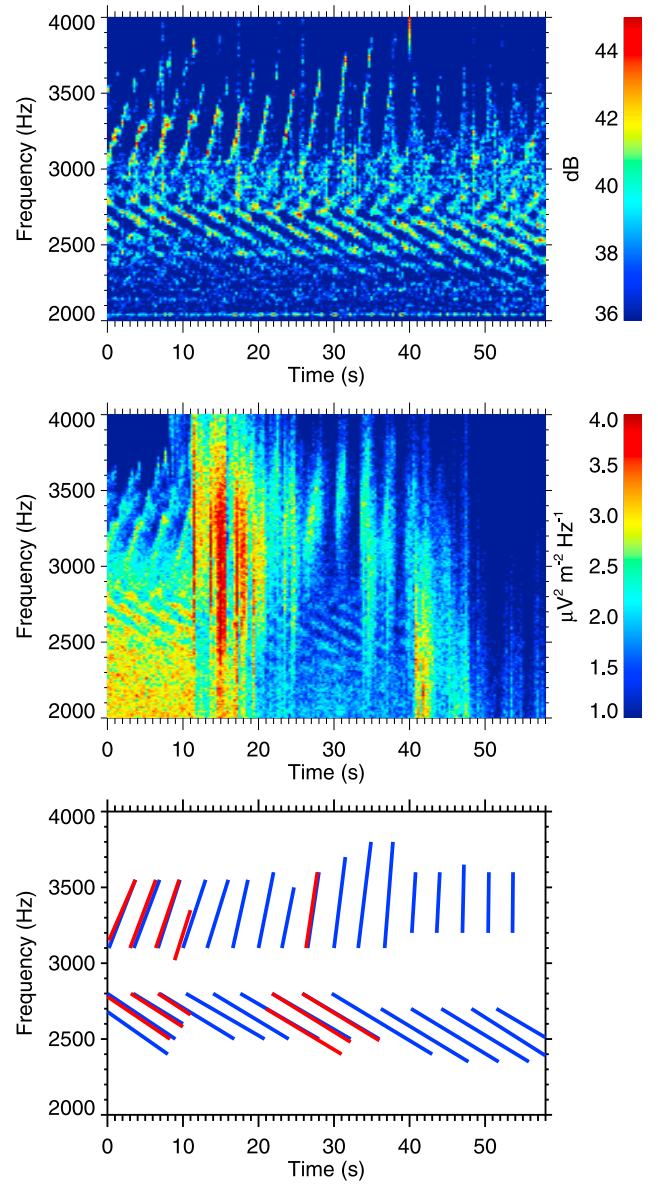

Figure 2. (top) Frequency-time spectrogram of the power spectral density of a signal recorded at the Kannuslehto station on March 1, 2008 after 19:06:03 UT. (middle) Frequency-time spectrogram of the power spectral density of electric field fluctuations observed by the DEMETER spacecraft on March 1, 2008 after 19:06:03 UT, corresponding to the time interval when DEMETER was in the Burst mode and passing close to the Kannuslehto station. (bottom) Schematic frequency-time spectrogram comparing Kannuslehto (in blue) and DEMETER (in red) data. 

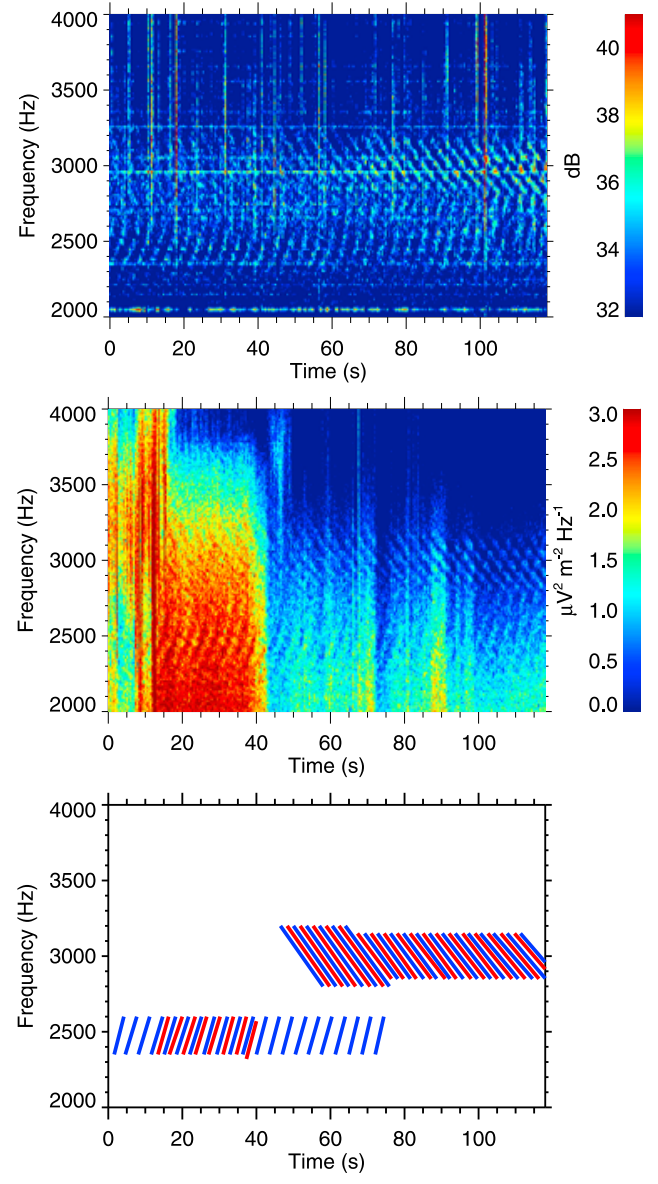

Figure 3. The same format as in Figure 2, but this time the data start on March 1, 2008 at 18:35:03 UT, corresponding to the time interval when DEMETER was passing close to the conjugate point of the Kannuslehto station and the Burst mode was active.

excellent agreement between the two, namely both the time intervals between the lines and their slope are the same. It seems that the satellite observes the emissions a bit earlier than the instruments on the ground: the mean time separation varies with frequency, but is about $0.4 \pm 0.1 \mathrm{~s}$.

[9] Time intervals between individual elements and the appropriate standard deviations have been determined using linear fits to the times when they were observed. It turns out that the time interval between the elements varies with frequency. For the lower band, the variation is rather small: the time delay is $3.79 \mathrm{~s}$ at $2400 \mathrm{~Hz}$ and $3.73 \mathrm{~s}$ at $2800 \mathrm{~Hz}$. However, for the upper band the variation becomes quite significant: the time delay is $3.35 \mathrm{~s}$ at $3100 \mathrm{~Hz}$ and $3.09 \mathrm{~s}$ at $3600 \mathrm{~Hz}$. The standard deviation is about $0.02 \mathrm{~s}$ for all the cases.

[10] Figure 3 uses the same format as Figure 2, but it represents the data measured after 18:35:03 UT when DEMETER was in the Burst mode and passing close to the region magnetically conjugate to Kannuslehto. Similarly to Figure 2, the satellite data are more noisy than the groundbased data, but the observed structure is approximately the same. Again, two different bands of emissions are present. The first one consists of rising tones at frequencies between about $2350 \mathrm{~Hz}$ and $2600 \mathrm{~Hz}$. The second one consists of falling tones at frequencies between about $2800 \mathrm{~Hz}$ and $3200 \mathrm{~Hz}$. Once more, the two bands are separated by a gap in which no particular emissions are observed. There is practically no dispersion effect in the lower band: the time delay is $3.54 \mathrm{~s}$ at $2350 \mathrm{~Hz}$ and $3.51 \mathrm{~s}$ at $2600 \mathrm{~Hz}$. However, in the upper band the dispersion is observable: the time delay is $3.64 \mathrm{~s}$ at $2800 \mathrm{~Hz}$ and $3.50 \mathrm{~s}$ at $3200 \mathrm{~Hz}$. The standard deviation is again about $0.02 \mathrm{~s}$ for all the cases.

[11] From the schematic representation in Figure 3 (bottom) it can be seen that the times when the individual elements are observed by the satellite (red color) are significantly shifted from the times when these elements are observed on the ground (blue color). This can be explained by the reflection of the elements between the hemispheres. Let us say that the element is first observed at the Kannuslehto station. Then it propagates along the magnetic field line to the Southern hemisphere where it is observed by the satellite close to the magnetically conjugate region. Finally, it is reflected and propagates along the magnetic field line back to the northern hemisphere and is detected again at the Kannuslehto station. The difference between the time of observation by the satellite and the time of observation by the ground-based instruments therefore approximately corresponds to the one-hop whistler mode travel time of the element between the hemispheres - it is equal to the half of the time separation of the elements observed on the ground (or on board the satellite).

\section{Discussion and Conclusions}

[12] The results presented in Figure 2 are an extension of the results reported by Parrot et al. [2007]. They showed that both the frequency and the intensity of the observed emissions are consistent between the DEMETER satellite and the Kannuslehto station. However, the structure of the emissions they studied (lines at nearly constant frequencies) did not allow them to check the timing between the spacecraft and the ground station. The recently observed emissions allow us to perform such a check, as presented in Figure 2 (bottom). It can be seen that the timing of individual elements agrees well between the satellite and ground-based measurement. The reason why the satellite observes the emissions a bit earlier is that as the wave comes along the magnetic field line from the southern hemisphere, it first encounters the satellite and then it must propagate some $660 \mathrm{~km}$ or more to reach the ground station.

[13] Such a careful check of the appropriate timing is important for the interpretation of the results presented in Figure 3 - it provides a useful information about the timing accuracy when comparing DEMETER and Kannuslehto data, supporting the explanation of two elements (one for each band of emissions) traveling along the magnetic field line between the hemispheres.

[14] Now we briefly discuss the propagation of electromagnetic waves between the hemispheres. The waves at these frequencies propagate in the right-handed polarized whistler mode, limited to the frequency range below the electron gyrofrequency $\left(f_{H}\right)$. At frequencies below $f_{H} / 2$ they may be trapped in the ducts of enhanced plasma density [Helliwell, 1965; Walker, 1993]. Supposing a dipole approximation of the Earth's magnetic field, one can make a simple estimate of the equatorial electron gyrofrequency $\left(f_{H e q}\right)$ along 
the field line passing through the Kannsulehto station $\left(\lambda_{m}=\right.$ $\left.64.37^{\circ}, L=5.34\right): f_{\text {Heq }} \simeq 5700 \mathrm{~Hz}$. The frequency of the gap in Figures 2 and 3 therefore approximately corresponds to $f_{\text {Heq }} / 2$, similarly as for chorus emissions [e.g., Burtis and Helliwell, 1976; Santolik et al., 2005]. Application of more sophisticated magnetic field models (leading in general to slightly lower values of $f_{\text {Heq }}$ ) does not help much, because the wave propagation path does not have to be so simple - most importantly the wave may be traveling at slightly lower L-shells, penetrating the ionosphere at lower geomagnetic latitudes and finally propagating towards the Kannuslehto station in the Earth-ionosphere waveguide. This would be consistent with the DEMETER observations being taken at these slightly lower geomagnetic latitudes (see Figure 1) and still containing the event.

[15] Concerning the time delay between individual elements, we can make the following analysis. For ducted propagation, the "nose" frequency $f_{n}$ of the minimum time delay can be estimated as $f_{n} \simeq 0.4 f_{\text {Heq }}$ [Sazhin et al., 1992]. This corresponds approximately to the frequencies of the observed lower bands of emissions, explaining why they exhibit almost no dispersion effect. Moreover, we have performed a calculation of the expected time delay supposing the dipole magnetic field $(L=5.34)$ and using a model profile of plasma density [Denton et al., 2004]. It turns out that rather typical equatorial electron densities at this L-value $\left(N_{e q} \simeq\right.$ $25-30 \mathrm{~cm}^{-3}$ ) are consistent with the observed time delays. The propagation of the emissions in the upper band is more complicated. Since $f>f_{\text {Heq }} / 2$, it is commonly supposed that they cannot be ducted [Walker, 1993]. However, in such a case it is very difficult to explain the periodic observations of individual elements in the conjugate regions. Moreover, these waves exhibit a clear dispersion effect - i.e., the time delay at larger frequencies is lower. There is also a question of the origin of the first element; we suggest that it could be similarly to the whistler-mode chorus - generated in the equatorial region by a temperature anisotropy of energetic electrons [Omura et al., 2008]. However, chorus elements are generated in series and have much larger frequency sweep rates.

[16] We have used the unique conjugate measurements on the ground and on board the low-altitude satellite in order to demonstrate that, once generated, the wave elements can bounce between the conjugate hemispheres for a long time without visible attenuation, forming an MLR-like event. Although this mechanism does not enable us to explain all observations of MLR events, at least some of them can be surely understood only by using such a simple scheme.

[17] Acknowledgments. DEMETER is currently operated by CNES and the corresponding staff is deeply acknowledged. We thank J. J. Berthelier, who is the PI of the electric field instrument. This work was supported by GACR grant 205/09/1253, ME grant 9107, GAUK grant 97909, AVCR grant M100420903, PICS grant 3725 from CNRS/DREI and LAPBIAT 2 program contract RITA-CT-2006-025969 from SGO, Finland.

\section{References}

Berthelier, J. J., et al. (2006), ICE, the electric field experiment on DEMETER, Planet. Space Sci., 54, 456-471.

Bullough, K. (1995), Power line harmonic radiation: Sources and environmental effects, in Handbook of Atmospheric Electrodynamics, vol. 2, pp. 291-332, CRC Press, Boca Ralton, Fla.
Burtis, W. J., and R. A. Helliwell (1976), Magnetospheric chorus: Occurrence patterns and normalized frequency, Planet. Space Sci., 24, 10071024.

Denton, R. E., J. D. Menietti, J. Goldstein, S. L. Young, and R. R. Anderson (2004), Electron density in the magnetosphere, J. Geophys. Res., 109, A09215, doi:10.1029/2003JA010245.

Helliwell, R. A. (1965), Whistlers and Related Ionospheric Phenomena, Stanford Univ. Press, Stanford, Calif.

Manninen, J. (2005), Magnetospheric line radiation, in Some Aspects of ELF-VLF Emissions in Geophysical Research, pp. 85-110, Sodankylä Geophys. Obs. Publ., Sodankylä, Finland.

Němec, F., O. Santolík, M. Parrot, and J. J. Berthelier (2007), Comparison of magnetospheric line radiation and power line harmonic radiation: A systematic survey using the DEMETER spacecraft, J. Geophys. Res., 112, A04301, doi:10.1029/2006JA012134.

Němec, F., O. Santolík, M. Parrot, and J. Bortnik (2008), Power line harmonic radiation observed by satellite: Properties and propagation through the ionosphere, J. Geophys. Res., 113, A08317, doi:10.1029/ 2008JA013184.

Němec, F., M. Parrot, O. Santolík, C. J. Rodger, M. J. Rycroft, M. Hayosh, D. Shklyar, and A. Demekhov (2009), Survey of magnetospheric line radiation events observed by the DEMETER spacecraft, J. Geophys. Res., 114, A05203, doi:10.1029/2008JA014016.

Nunn, D., J. Manninen, T. Turunen, V. Trakhtengerts, and N. Erokhin (1999), On the nonlinear triggering of VLF emissions by power line harmonic radiation, Ann. Geophys., 17, 79-94.

Omura, Y., Y. Katoh, and D. Summers (2008), Theory and simulation of the generation of whistler-mode chorus, J. Geophys. Res., 113, A04223, doi:10.1029/2007JA012622.

Parrot, M., F. Němec, O. Santolík, and J. J. Berthelier (2005), ELF magnetospheric lines observed by DEMETER, Ann. Geophys., 23, 3301-3311.

Parrot, M., A. Buzzi, O. Santolík, J. J. Berthelier, J. A. Sauvaud, and J. P. Lebreton (2006a), New observations of electromagnetic harmonic ELF emissions in the ionosphere by the DEMETER satellite during large magnetic storms, J. Geophys. Res., 111, A08301, doi:10.1029/ 2005JA011583.

Parrot, M., et al. (2006b), The magnetic field experiment IMSC and its data processing onboard DEMETER: Scientific objectives, description and first results, Planet. Space Sci., 54, 441-455.

Parrot, M., J. Manninen, O. Santolík, F. Němec, T. Turunen, T. Raita, and E. Macúšová (2007), Simultaneous observation on board a satellite and on the ground of large-scale magnetospheric line radiation, Geophys. Res. Lett., 34, L19102, doi:10.1029/2007GL030630.

Rodger, C. J., N. R. Thomson, and R. L. Dowden (1995), VLF line radiation observed by satellite, J. Geophys. Res., 100, 5681-5689.

Rodger, C. J., M. A. Clilverd, K. H. Yearby, and A. J. Smith (1999), Magnetospheric line radiation observations at Halley, Antarctica, J. Geophys. Res., 104, 17,441-17,447.

Rodger, C. J., M. A. Clilverd, K. Yearby, and A. J. Smith (2000a), Is magnetospheric line radiation man-made?, J. Geophys. Res., 105, $15,981-15,990$

Rodger, C. J., M. A. Clilverd, K. H. Yearby, and A. J. Smith (2000b), Temporal properties of magnetospheric line radiation, J. Geophys. Res., $105,329-336$.

Santolík, O., E. Macúšová, K. H. Yearby, N. Cornilleau-Wehrlin, and H. S. K. Alleyne (2005), Radial variation of whistler-mode chorus: First results from the STAFF/DWP instrument on board the Double Star TC-1 spacecraft, Ann. Geophys., 23, 2937-2942.

Sazhin, S. S., M. Hayakawa, and K. Bullough (1992), Whistler diagnostics of magnetospheric parameters: A review, Ann. Geophys., 10, 293-308. Walker, A. D. M. (1993), Plasma Waves in the Magnetosphere, Springer, Berlin.

F. Němec and M. Parrot, Laboratoire de Physique et Chimie de l'Environnement et de l'Espace, CNRS, 3A Avenue de la Recherche Scientifique, F-45071 Orléans CEDEX 2, France. (frantisek.nemec@gmail. com; mparrot@cnrs-orleans.fr)

T. Raita and T. Turunen, Sodankylä Geophysical Observatory, Tähteläntie 62, FIN-99600 Sodankylä, Finland. (tero.raita@sgo.fi; tauno.turunen@ sgo.fi)

O. Santolík, Institute of Atmospheric Physics, ASCR, Boční II 1401, 14131 Prague 4, Czech Republic. (os@ufa.cas.cz) 